\title{
LOS DERECHOS HUMANOS Y LA ANALOGÍA HERMENÉUTICA
}

\section{HUMAN RIGHTS AND HERMENEUTICAL ANALOGY}

\author{
NAPOLEÓN CONDE GAXIOLA \\ Instituto Politécnico Nacional, México
}

Recibido: 15/02/2019 Aceptado: 18/09/2019

\section{RESUMEN}

El presente texto constituye una reflexión sobre la especificidad de la hermenéutica analógica, para abordar el estudio de los derechos humanos. La perspectiva es humanista y crítica, ya que evita caer en el marco del positivismo jurídico, de factura reglamentarista y normativista, basada en la coacción; por otro lado, se mantiene distante de las esferas de la posmodernidad tan frecuente en nuestro medio. Señalamos que la hermenéutica analógica nos sirve a nivel teórico y metodológico para comprender el diálogo, el bien común, la frónesis y la ontología, aplicadas a la naturaleza del hombre, con el propósito de tener una visión más amplia y cabal de los derechos humanos en el marco de la filosofía del Derecho.

Palabras clave: Hermenéutica analógica, Derechos Humanos, Analogía, Relativismo, Univocismo.

\section{ABSTRACT}

This paper constitutes a reflection on the specificity of analogical hermeneutics, to address the study of human rights. The perspective is humanistic and critical, since it avoids falling within the framework of legal positivism, regulatory and normativist invoice, based on coercion; on the other hand, it remains distant from the spheres of postmodernity so prevalent in our context. We point 
out that analogical hermeneutics serves us at the theoretical and methodological level to understand dialogue, the common good, phrónesis and ontology, applied to the human nature, with the purpose of having a broader and more comprehensive view of human rights in the framework of the philosophy of law.

Keywords: Analogical hermeneutic, Human Rights, Analogy, Relativism Univocism.

Sumario: 1. Introducción. 2. Desarrollo. 3. Conclusión

\section{INTRODUCCIÓN}

En este trabajo pretendemos reflexionar sobre la temática de los derechos humanos desde el punto de vista de la analogía y la hermenéutica. Para ello nos auxiliamos de una concepción humanista, para tratar de configurar una hermenéutica jurídica de hechura ética, antropológica y ontológica, sin ignorar su dimensión económica, política y social. Tratamos de esquivar el lineamiento univocista y equivocista, para centrarnos en una postura de mayor apertura, con la idea de comentar las nociones de bien común, comunidad, democracia, el linchamiento, la interpretación, la ontología, la ley natural y la ética, así como otros puntos parecidos. La pregunta de investigación es la siguiente: ¿hasta qué punto es pertinente una dimensión analógica, para estudiar los derechos humanos desde una óptica alternativa, al margen de los criterios positivistas y del relativismo jurídico? Veamos en qué medida puede existir la posibilidad de lograr esta importante tarea y desafío. En ese sentido nuestro trabajo ha sido, generar puntos de vista significativos en relación al tópico del derecho y de los derechos humanos. 


\section{DESARROLLO}

De manera muy breve, podemos definir a la hermenéutica como aquella disciplina que tiene por objeto la interpretación de textos. En esa vía, si el derecho y los derechos humanos son un texto, la hermenéutica es el saber por excelencia, pero bajo la forma de hermenéutica jurídica. Por otro lado, la analogía ha sido históricamente muy pertinente en el derecho., la cual se ha utilizado, sobre todo, en la teoría del derecho y la jusfilosofía ${ }^{1}$. De hecho, el hermeneuta mexicano, creador de la hermenéutica analógica, Mauricio Beuchot, la ha abordado en diversos textos ${ }^{2}$ y materiales 3 .

"De alguna manera, se puede hablar de que la hermenéutica analógica ha acompañado al derecho. En efecto, el procedimiento por analogía se ha dado de manera muy amplia por él. Por analogía se encuentran las leyes que se ajustan a los casos, o los casos que se ajustan a las leyes"4.

Históricamente, la analogía y la hermenéutica han asistido no sólo a la justicia sino al derecho mismo. De esta forma, se ubica la correspondencia entre los principios y las reglas, las formas morales y las leyes. Para un derecho humanista tiene que existir una estabilidad proporcional entre lo formal y lo axiológico; lo primero es típico del normativismo, y lo valorativo es típico de lo segundo. Tal situación puede ser resuelta por la iconicidad. Esta última se vincula con la phrónesis, que es la prudencia de los jueces y legisladores con una actitud humanista. La jurisprudencia, al igual que la legislación, debería ser una actividad analógica.

\footnotetext{
1 Alejandro Rosillo, coord., Hermenéutica analógica. Derecho y filosofía (México: Facultad de Derecho de la Universidad Autónoma de San Luis Potosí, 2007).

2 Mauricio Beuchot, Filosofía del derecho, hermenéutica y analogía (Bogotá: Universidad de Santo Tomás, 2006).

3 Mauricio Beuchot, Reflexiones filosóficas sobre los derechos humanos (México-Madrid: Universidad Nacional Autónoma de México-Tirant lo Blanch, 2018).

4 Beuchot, Reflexiones filosóficas..., 18 y 19.
} 
Igual sucede con la justicia, entendida como una virtud indispensable en el ejercicio del derecho.

Como vemos, la analogía hermenéutica puede ofrecernos algunas herramientas para comprender la ciencia jurídica. En ese camino, la hermenéutica es una ciencia y un arte. La primera como un cuerpo sistematizado de saberes, en la que son importantes los conceptos, los métodos y los principios, permitiendo la estructuración de los temas a nivel inductivo, deductivo y abductivo. En este contexto es fundamental la intelección dentro del entendimiento y, el razonamiento en la explicación para llevarla a la teoría y a la práctica. Por otro lado, es arte o técnica en el sentido aristotélico, es decir, una agrupación de reglas que nos permiten ordenar la sensibilidad y la creación, desde un punto de vista interpretacional 5 , tal como lo ubica Beuchot en su texto sobre los fundamentos de la hermenéutica analógica ${ }^{6}$. Al constituirse como ciencia y como arte, está en condiciones para abordar de manera subjetiva y objetiva, no sólo el derecho sino también los derechos humanos. El derecho supone un modelo de ser humano, por donde emerge una verdad política, histórica y subjetiva; política porque indica la búsqueda del bien común; histórica porque se basa en una comprensión de lo pretérito, lo actual y el porvenir; es decir, ubicado en el devenir global de la sociedad, y subjetiva porque se trata de un sujeto capaz de tomar decisiones para superar su condición de animal humano y transitar de la interpretación a la acción. Para ello es viable adoptar una posición práctica de defensa real de los derechos humanos, tan dúctil en el campo legalista, por su olvido de los criterios morales y políticos.

"Los derechos humanos corresponden a una idea del hombre, de la cual surge una ética y una filosofía política. Se trata de un modelo de antropología filosófica, que subyace a la idea de tales derechos. Por eso tenemos que buscar, aunque sea someramente, a qué idea o modelo

5 Robert Kilwardby, De ortu scientiarum (London: British Academy, 1976), 145-146.

6 Mauricio Beuchot, Tratado de hermenéutica analógica. Hacia un nuevo modelo de interpretación, $2^{\mathrm{a}}$. ed. (México: UNAM/Itaca, 2000), 18. 
de hombre corresponden los derechos humanos y se pueden apoyar en él"7.

Es relevante adoptar un punto de vista humanista, tan extraño en nuestro tiempo, sobre el hombre; es decir, una antropología filosófica como saber orientado a explorar la esencia del ser humano. Se trata de un personalismo crítico, capaz de privilegiar la naturaleza humana por encima de la normatividad y de las posturas jurisprudencialistas. Lo importante es el sujeto humano ubicado al margen del positivismo jurídico ${ }^{8}$ y distanciado de la posmodernidad relativista ${ }^{9}$. Tal aspiración conduce a visualizar al jurista como núcleo o centro de intencionalidades; es por ello que el hombre, además de ser un animal hermenéutico es un animal analógico. La antropología filosófica es diagramática, pues se atiene más al modelo de hombre que presentemos, que a las normas y reglas abstractas ofrecidas por el cientificismo objetivista y legalista del derecho.

En realidad, todo humanismo es atravesado por el modelo de hombre, es decir, se adhiere a una antropología filosófica. Se trata de un personalismo analógico apuntalado en la idea de persona, y analógico porque explora lo primordial de la existencia. En esa vía sitúa al hombre como microcosmos, como un compendio de todo el ser, agrupando en sí mismo la totalidad del horizonte o macrocosmos. "En efecto, a toda empresa humana le subyace una idea del ser humano, esto es, una antropología filosófica o filosofía del hombre. Y aquí deseo articularla desde la hermenéutica analógica”10.

En una propuesta hermenéutica, los derechos humanos se mantienen forzosamente en un tejido interpretacional del hombre, de la cultura, de la formación social, históricamente determinada, logrando una caracterización legitima de los derechos humanos planteados. Es una

\footnotetext{
7 Beuchot, Reflexiones filosóficas sobre los derechos humanos..., 21.

8 Hans Kelsen, Teoría pura del derecho (México: UNAM, 1982), 15-67.

9 José Calvo, Derecho y narración. Materiales para una teoría y crítica narrativista del Derecho (Barcelona: Ariel, 1996), 73-96.

10 Mauricio Beuchot, Reflexiones filosóficas sobre los derechos humanos..., 21.
} 
comprensión crítica del ser humano, en función de sus proyectos y propuestas, para ubicar los derechos primordiales a los que se refiere. Es por eso que, a todo dispositivo teórico dirigido hacia una acción práctica le concierne evitar los extremos para lograr un equilibrio relativo.

"Aquí trataré de aplicar la hermenéutica analógica para lograr una mejor comprensión de los derechos humanos, sobre todo cuando son entendidos de manera diferente por las culturas que conviven en algún país. A pesar de que la hermenéutica analógica privilegia las diferencias, lo hace sin perder la capacidad de universalizar, que es lo que se necesita en los derechos humanos"11.

Eso implica darse cuenta de las diferencias y contradicciones con el propósito de no afectar la esencia de los derechos humanos; sortear la falacia naturalista, como pretexto del positivismo jurídico, para separarse de la ética, planteando un derecho deshumanizado. En la época moderna, se privilegió la separación de la ética del derecho; en la actualidad existe un esfuerzo por volver a ligarlos. Es por eso que se debe entender de manera prudente la aplicación de los derechos humanos en un contexto intercultural. Al menos en México, y en buena parte de América Latina, se comprende de manera diferente a los derechos humanos, como sucede en el caso del linchamiento.

En las comunidades indígenas, en el ámbito rural o en las zonas comunitarias urbanas de algunas delegaciones o alcaldías, se concibe de manera complicada el linchamiento de los presuntos delincuentes por la colectividad $^{12}$. Para algunas comunidades es una ejecución masiva sin proceso legal, fuera del derecho positivo, al margen del Estado, cumpliendo el mandato popular para castigar a un sujeto determinado o a un cacicazgo, el cual, desde la perspectiva de esa comunidad, sería

11 Mauricio Beuchot, "La hermenéutica analógica en la comprensión de los derechos humanos", Hiperbórea 1 (2010): 7.

12 Juan Pablo Aguirre Quezada, Linchamientos en México (Ciudad de México: Cuaderno de investigación 39, Dirección General de Análisis Legislativo, Instituto Belisario Domínguez, Senado de la República, 2018), 30. 
exonerado por las autoridades oficiales. La experiencia de la policía comunitaria en Guerrero, de las autodefensas en Michoacán, y del Ejército Zapatista de Liberación Nacional en Chiapas, indican la complejidad de la resolución dialéctica de tales contradicciones. A veces, los participantes en un linchamiento lo aplican a individuos inocentes; en ocasiones, al juzgar sin un juicio se comenten excesos. Sin embargo, algunas ocasiones constituyen una respuesta masiva frente a la impunidad, por ejemplo, ante el cansancio de la comunidad en la violación de niños, asaltos o ajusticiamientos de los delincuentes a la población civil ${ }^{13}$. La pregunta es: ¿cómo se aplican los derechos humanos en zonas en conflicto?, ¿puede ser posible la existencia de tribunales populares?, ¿̇cuáles son los derechos humanos de narcotraficantes al ser detenidos por sus arbitrariedades y cómo deberán ser tratados por el llamado poder comunal o barrial? Al aplicar la jusanalogía se deben privilegiar las diferencias ubicando el problema, más allá del sistema jurídico dominante, para tratar de enlazarlo con la ética y una antropología filosófica, pues si la moralidad se exprime a sí misma, en consecuencia se autoanula. Incluso el pospositivismo señala que el derecho funciona mejor si es ético ${ }^{14}$. La propuesta de que los derechos humanos se convierten en derechos morales es una realidad evidente. Es claro que la solución al llamado linchamiento debería ser analógica y dialéctica; para no caer en el marco estricto del derecho positivo, entregando a los delincuentes a las instituciones establecidas, para inmediatamente, debido a la impunidad, obtener su libertad ${ }^{15}$. La dialéctica propone resolver las contradicciones evitando la venganza y el derramamiento gratuito de sangre, procurándose justicia por sí mismos, sorteando el desquite en el futuro de los delincuentes sobre la misma comunidad. La ética se fundamenta en una filosofía del ser humano. Si la ética no se mantiene en un personalismo, se podrá

13 Carlos Monsiváis, "Los linchamientos: el crimen a nombre de la justicia popular", Proceso 14 de septiembre de 1996.

14 Manuel Atienza y Juan Ruíz Manero, "Dejemos atrás el positivismo jurídico”, Revista Isonomía 27 (2007): 14-15.

15 Raúl Rodríguez Guillén, "Crisis de autoridad y violencia social: los linchamientos en México", Polis 8 (2012): 43-74. 
convertir en una pseudo-ética, es decir, en una completa inhumanidad. De ahí la importancia de un modelo de ser humano, tan ausente en los diversos positivismos, sean éstos excluyentes, incluyentes o axiológicos. Sin duda alguna, no se han resuelto, al menos en México, la tipificación de los derechos humanos y la especificidad de su aplicación en situaciones concretas. Lo más fácil sería ofrecer recetas sencillas para grandes problemas. Por lo pronto, señalamos mínimamente los criterios; no del todo concluidos sobre tal situación. Es interesante la siguiente reflexión:

"Pues bien, todas esas actividades hermenéuticas y analógicas las hace el hombre en medio del diálogo, en el seno de una comunidad. En efecto, la analogización, puesto que tiene como elemento connotado el distinguir para poder unir convenientemente, se da sobre todo en la discusión, en el diálogo; y éste se da en la comunidad"16.

Es decir, pese a toda la crítica a la dialogicidad, la posibilidad de una conversación hermenéutica entre los aliados y los opuestos podría ofrecer mayor apertura para la comprensión de los derechos humanos. Tal pretensión, podría mover a risa a algunos. En ese sendero, también es importante el papel de la comunidad, pues en ella están los símbolos que nos sirven para ubicar lo metafórico de sus aspiraciones tratando de la búsqueda del sentido. También se ubica la metonimia para visualizar la referencialidad; por eso me parece importante la idea de un personalismo analógico orientado a resolver los problemas del hombre en la comunidad, su ubicación como persona con cualidades y defectos, y el marco histórico, económico y político, de sus deseos y ambiciones. Es importante, la conexión entre derecho y analogía hermenéutica, pues nos da la clave para evitar una acción univocista, propia de las teorías jurídicas normativistas y traer la exclusión, la dictadura y el autoritarismo. Una posición equívoca pretenderá que los derechos humanos se anclen

16 Mauricio Beuchot, Antropología filosófica. Hacia un personalismo analógico-icónico (Salamanca, Colección Persona, 2008), 108. 
únicamente en la diferencia, promoviendo eternamente la interpretación infinita y la espontaneidad.

"La hermenéutica analógica será. Pues, la que nos dé una comprensión adecuada de los derechos humanos en un contexto multicultural, sin el absolutismo individualista del liberalismo ni el relativismo colectivista del comunitarismo ni el relativismo individualista del posmodernismo"17.

En efecto, históricamente el liberalismo ha planteado una postura unidimensional de los derechos humanos al hegemonizar el poder del Estado y de las instituciones, situándose por encima de la comunidad. A su vez, los diversos tipos de comunitarismo han caído en el populismo, en el totalitarismo o en un falso colectivismo. Por eso es necesario una perspectiva analógica, la cual partirá de la dignidad y sobre todo de la naturaleza humana, como ha sido planteado por el jusnaturalista alemán Ernst Bloch, en la que el Estado y el derecho mismo no tienen la última palabra $^{18}$. De ahí la desconfianza de la colectividad respecto a los tribunales y hacia el ojo de la ley ${ }^{19}$. La dicotomía podría reducirse con un uso adecuado de los derechos humanos por los diversos actores de las clases sociales o tal vez, por cierta transculturalidad de corte analógica, situada más allá de la constelación cultural de la sociedad, sin olvidar los intereses económicos y políticos de los grupos en pugna.

Aristóteles, en su texto Política, dice: "el hombre es por naturaleza un animal social"2o, Tomas Hobbes caracteriza al hombre como "un auténtico lobo para el hombre" ${ }^{21} \mathrm{y}$ para Marx piensa que el hombre se define en función del conflicto social: "hombres libres y esclavos, patricios y plebeyos, señores y siervos, maestros y oficiales, en una palabra: opresores y oprimidos se enfrentaron siempre, mantuvieron una lucha

17 Beuchot, "La hermenéutica analógica", 13.

18 Ernst Bloch, El principio esperanza, vol. 2 (Madrd: Trotta, 2006), 68.

19 Ernst Bloch, Derecho natural y dignidad humana (Madrid: Biblioteca Jurídica Aguilar, 1980), 184.

20 Aristóteles, Política, 1252b9 (Madrid: Gredos, 1988), 50.

21 Tomas Hobbes, De Cive (Madrid: Alianza Editorial, 2016), 34. 
constante, velada unas veces y otras franca y abierta"22. El filósofo francés, Michel Foucault, plantea "la muerte del hombre", al decir, al final de su libro Las palabras y las cosas: "El hombre es una invención cuya fecha reciente muestra con toda facilidad la arqueología de nuestro pensamiento. Y quizá también su próximo fin”23. A lo largo y ancho de la historia, se ha buscado el sentido del ser de la persona humana. Se ha tratado de caracterizar de la mejor manera posible lo que significa la naturaleza humana.

"Una hermenéutica unívoca interpretará al hombre como bueno por naturaleza, como social por naturaleza, no necesitado de pacto e incluso ni de leyes, como quiso Platón en La república, y lo corrigió en Las leyes. Una hermenéutica equívoca dará por malo al hombre, por antisocial, violador de pactos y que tiene un ámbito relativista para sus costumbres" 24 .

En cambio, una propuesta analogizante visualizará al ser humano como un actor social, económico y político, inserto en una situación comunal y en un pacto con otras clases sociales para configurar una buena convivencia.

En efecto vemos, siguiendo a Beuchot, la necesidad de un equilibrio entre la visión del derecho natural y del positivismo jurídico para obtener de manera más adecuada y prudente la idea de una naturaleza humana. Una perspectiva absolutista podrá llevarnos a una interpretación metonímica, puntual, al pie de la letra, es decir, rígida de los derechos humanos; observada y aplicada por las instituciones oficiales y por la decisión administrativa, judicial, fiscal y legislativa. Por otro lado, una posición equívoca nos conducirá a un indeterminismo y a una ambigüedad irracional. En otro ángulo, una postura más prudente buscará una razón analógica distante del liberalismo y de la posmodernidad. Es necesaria

22 Carlos Marx y Federico Engels, Manifiesto del Partido Comunista (Moscú: Editorial Progreso, 1969), 80.

23 Michel Foucault, Las palabras y las cosas (Buenos Aires: Siglo XXI Editores, 1968), 375.

24 Beuchot, "La hermenéutica analógica", 15. 
la construcción de un concepto de persona, como hemos tratado de hacerlo, para tipificar a los derechos humanos, así como su propuesta de sociedad y formas de convivencia. El mismo humanismo jurídico ${ }^{25}$ y la jus-fenomenología ${ }^{26}$, como jus-filosofía, han tratado de llevar agua a su molino.

"Vistos desde la fenomenología, propia de la filosofía del derecho, los derechos humanos responden a la búsqueda del bien común. Es verdad que en la política la modernidad olvidó esa categoría, y se polarizó hacia el poder; pero en los tiempos más recientes se ha tratado de recuperar, no sólo para la filosofía política, sino también para la filosofía del derecho. En este último ámbito, el bien común ha sido visualizado por los politólogos y juristas"27.

La cuestión del bien común ha sido despreciada por los positivis$\operatorname{mos}^{28}$ y los totalitarismos unívocos ${ }^{29}$, así como también por el relativismo; un ejemplo lo encontramos en el profesor griego Costas Douzinas al proponer que: "para defender al ser humano debemos atacar el humanismo, una combinación banal de metafísica clásica y cristiana (...) los derechos humanos del Otro podrían convertirse en el principio de justicia posmoderno" 30 . Estas teorías jurídicas han negado la idea humanista de la conexión entre los derechos humanos y el bien común. El polo opuesto es Ernst Bloch, al entender la esperanza como principio o derecho humano, planteando la trascendencia mediante la utopía. El hombre se realiza comunitariamente, ya que hay hombre en la medida que existe la utopía y la esperanza, de la que emergen los criterios morales, vitales y axiológicos como: bien común, vida buena, principios, trascendencia y

25 Luis Recaséns Siches, Introducción al estudio del derecho (México: Editorial Porrúa, 1997), 322 y 323.

26 Mariano Crespo, "Fenomenología y filosofía del derecho", Pensamiento 72 (2016): 1247-1261.

27 Beuchot, Reflexiones filosóficas sobre los derechos humanos..., 27.

28 Hans Kelsen, Teoría general del derecho y del Estado (México: Universidad Nacional Autónoma de, 2008), 215-245.

29 Andrey Vyshinsky, La teoría de la prueba en el derecho soviético (Montevideo: Editorial Nuevo derecho, 1951).

30 Costas Douzinas, "El fin(al) de los derechos humanos", Anuario de Derechos Humanos. Nueva Época 7 (2006): 312. 
colectividad. El hombre tiene un tejido antropológico y ontológico dirigido a la esperanza; por lo que la trascendencia y el bien común sea un punto básico en sus ideas. Por eso presenta a la persona, como aquel individuo que no se contenta con la injusticia, la indignidad, la inmanencia, para proponer una vida en el marco de la esperanza y la utopía; para ello, se constituye en comunión, mediante la búsqueda de una esencia verdadera, bajo una estructura política, histórica y societal. Es por eso el rechazo al derecho positivo del nacional-socialismo basado en el utilitarismo, la instrumentalización, el racismo, el negocio y la falta de trascendencia.

"Derecho es lo que aprovecha al pueblo alemán, es decir, al capital financiero; verdad es lo que fomenta la vida, es decir, la ganancia máxima, lo que más la sirve. Éstas han sido, por tanto, una vez que los tiempos se hubieron cumplido, las consecuencias del pragmatismo; y que inocentemente, engañosamente incluso, quería también aparecer como <teoría-praxis >. Aparentemente se negaba una verdad por razón de sí misma, pero sin decir que se hacía por razón de una mentira y del negocio" ${ }^{31}$.

La idea jusnaturalista sobre los derechos humanos explorando el bien común, es propia de un derecho natural crítico y alternativo, contrario a la negación de la vida en colectividad, al plantear la necesidad de resolver los complejos problemas de la humanidad, desde la naturaleza humana enlazándola con la praxis. Bloch adopta una postura autotélica, pues el hombre debe tener un fin basado en la perspectiva y el anhelo apuntando como un telos, construido hacia el devenir. Más que un miedo hacia el futuro, formula una conciencia de la posibilidad, enteramente utópica y esperanzadora. Por eso los derechos humanos son un ejercicio analógico, en la medida en la que están orientados a la búsqueda de la justicia y hacia la cristalización de la equidad. Así vemos que para la plena realización de los derechos humanos tiene que haber una

31 Ernst Bloch, El principio esperanza, vol. 1 (Madrid: Trotta, 2004), 326. 
democracia auténtica basada en el respeto a la persona, en la igualdad económica y política.

"Para la existencia de los derechos humanos, se requieren ciertas condiciones como un Estado de derecho, que puede establecer válidamente los derechos y defenderlos por la coacción para hacerlos cumplir; es el aspecto de la positivación. Y tal Estado es democrático, porque sólo en la democracia pueden darse la igualdad ante la ley y la libertad, pero se requiere, además, de la responsabilidad y la solidaridad para que también crezca la igualdad social" ${ }^{2}$.

Se trata pues, de una idea analógica de democracia basada en la igualdad no sólo social, cultural, jurídica y política, sino sobre todo económica. Aspecto aún no logrado en el liberalismo. Su propósito implica dirigir a los grupos humanos en beneficio de la colectividad. Los actores entienden que el hombre mismo se conduce a una sociedad más amable y decente guiada por la analogía, la prudencia, el consenso y la proporción. La democracia verdadera es la presencia de la esperanza como utopía jurídica, buscando la paz y la decencia, lejos del autoritarismo, la exclusión y la marginación. El fracaso de la sociedad de la competencia y del espectáculo 33 nos debe conducir a adoptar una actitud analógica, ante el modelo de sociedad en el que hemos vivido. Ha quedado atrás el esquema garantista del positivismo, ${ }^{34}$ basado en el cientificismo, la analítica y el normativismo. También ha fracasado los intentos populistas de hechura totalitaria basados en la subordinación ideológica de la masa al dictador. El ser humano no puede ser engañado con los impulsos relativistas de la sociedad débil,35 rizomática ${ }^{36}$ y seductora ${ }^{37}$ orientada a llevarnos al nihilismo activo y pasivo. Para esta crítica es vertebral la

32 Beuchot, Filosofía del derecho..., 178.

33 Guy Debord, La sociedad del espectáculo (Santiago de Chile: Ediciones Naufrago, 1995), 8.

34 Luigi Ferrajoli, Principia iuris, tomo I (Madrid: Editorial Trotta, 2007), 3-80.

35 Gianni Vattimo y Santiago Zabala, Comunismo hermenéutico. De Heidegger a Marx (Madrid: Editorial Herder, 2012), 121-164.

36 Gilles Deleuze y Felix Guattari, Mil mesetas: capitalismo y esquizofrenia (Madrid: Editorial Pre-textos, 2004), 9-32.

37 Jean Baudrillard, Cultura y simulacro (Barcelona: Editorial Kairós, 1978), 5-8. 
analogía, como teoría y método, estructurada bajo un humanismo jurídico, de carácter fronterizo y dialógico.

"Esta hermenéutica está vertebrada por la noción de proporción, trabajada por la idea de analogía, es decir es una hermenéutica analógica, que eludirá la cerrazón de la unívoca, para la cual sólo hay una interpretación válida, y las demás son todas falsas. Y también sorteará la equívoca, para la cual prácticamente todas las interpretaciones son válidas, y no hay ninguna falsa. En cambio, para una hermenéutica analógica, en el espíritu aristotélico, hay más de una interpretación válida: puede haber varias, pero todas jerarquizadas de mejor a peor, con una gradación que va desde la más apropiada hasta la que lo es menos, donde ya comienza la inadecuación"38.

En esa medida será pertinente la ontología como saber orientado a encontrar la esencia misma de las cosas, donde la forma social sea un territorio de la esperanza y de la iconicidad. Lejos de la ontología del fisicalismo y de la equivocidad. También es una propuesta en la que es importante la phrónesis o proporción. 39 Ésta se entiende como una forma de sabiduría práctica relacionada con la mesura. También es una virtud teórica, mas eso no implica únicamente la contemplación sino la misma facticidad. Sobre todo es proporción, ya que precisa el equilibrio analógico de lo particular y de lo universal. Nos auxilia a ubicar la medianía y el horizonte medio de la reflexión y de la acción, pues nos da la pauta para acercarnos teleológicamente a nuestros objetivos. Es una sabiduría de lo múltiple y de lo empírico. Es en síntesis la analogía puesta en escena. En otro ángulo agrupa segmentos otorgándoles un cierto orden y estructura. Nos ayuda al otorgarnos las bases para dialogar, interpretar y tomar decisiones. Abordar los derechos humanos desde el punto de vista de la proporción, es adoptar un esquema mediador de factura

38 Mauricio Beuchot "El uso de la hermenéutica y la analogía en el derecho", en Mauricio Beuchot y Napoleón Conde, Esbozo analógico para el derecho y las ciencias sociales (México: Editorial Torres, 2018), 26.

39 Mauricio Beuchot, Phrónesis, analogía y hermenéutica (México: UNAM, 2007), 105 y ss. 
fronética, orientado a evitar la irracionalidad, la improvisación y el simulacro. En este horizonte es importante la equidad, que no es otra cosa que la justicia puesta en práctica. Para comprender los derechos humanos es pertinente entender las virtudes teóricas y prácticas.

"Tal sucede en dos virtudes que son altamente analógicas, a saber, la prudencia o phrónesis, de la cual viene la jurisprudencia, y la equidad o epeiqueia, que es la aplicación adecuada de la ley, que es general, al caso concreto, que es particular. La jurisprudencia es la aplicación correcta de la ley a casos difíciles o que no están explicitados en ella, por medio de leyes semejantes o de casos parecidos, hasta llenar las lagunas o implementar leyes nuevas que satisfagan el punto. La equidad es un paso más, es la sutileza para aplicar la ley al caso concreto, buscando el bien de las partes, de modo que no se lastime a nadie sino que, antes bien, se ayude a todos a avanzar en la vida social. Y la sutileza es una virtud hermenéutica, la más propia del hermeneuta o intérprete, la cual aquí se ve aplicada al derecho, en la virtud de la equidad, aparejada a la de la prudencia jurídica" ${ }^{\circ 0}$.

Se ha tocado el papel de las virtudes, lo cual es necesario no sólo en el derecho sino también en los derechos humanos; Beuchot reflexiona sobre la frónesis y la equidad y también sobre la sutileza, ésta es entendida como el encuentro de una posibilidad en donde nadie la vislumbraba; por eso es una virtud y también un método, entendido como el camino o sendero para descubrir algo significativo; es por eso que a Juan Duns Escoto se le conocía como "Doctor Sutil” por su enorme capacidad para explorar veredas desconocidas y volverlas espacios con claridad41. También tenía que ver con su teoría de las distinciones expresada en la distinctio formalis ex natura rei, ubicada entre la razón y lo real. Tales distinciones podrían ayudar con la diferenciación en el entendimiento de los textos, conduciendo a una mejor puntualidad y regularidad, logrando

40 Beuchot, Reflexiones filosóficas sobre los derechos humanos..., 24 y 35.

41 Maurice J. Grajewski, "The Formal Distinction of Duns Scotus", The Philosophical Review 56 (1947): 448-449. 
una recolección más adecuada. Como vemos, la sutileza supone una exquisitez, así como una honra y un refinamiento estructurado como virtud, la cual es indispensable no sólo para comprender la Edad Media, sino como un artífice para entender el mundo actual. El propio Beuchot indica que la subtilitas estuvo asociada con la hermenéutica y es la metodología de su hermenéutica analógica. Él establece que la subtilitas implicandi tocaría a la sintaxis; la subtilitas explicandi, a la semántica, y la subtilitas aplicandi correspondería a la pragmática ${ }^{42}$. Es una metodología humanista, abierta e icónica, contraria al instrumentalismo de la modernidad y la tardomodernidad, basada en consecuencia en lo intratextual, lo intertextual y lo contextual respectivamente.

Además de lo dicho con anterioridad, otro tópico importante en la hermenéutica jurídica es el de la ontología, pues explora el analogado principal del derecho. Una ontología positivista plantearía que la esencia del derecho es la coacción; aunque Hans Kelsen rechaza una ontología jurídica. En ambos casos se adopta una actitud univocista. Una ontología analógica identifica la esencia del derecho con la justicia, por medio de la distinción identifica los grados del ser. Es una ontología que respeta las "otras" ontologías, sean estas absolutistas o subjetivistas.

"Esta hermenéutica acepta una ontología. Ésta última es una ontología también analógica, es decir, distingue diversos órdenes del ser, no es cerrada como la unívoca, ni demasiado abierta y atomizada como una equívoca. Es una hermenéutica que admite más de una interpretación como válida, a diferencia de la unívoca, pero no todas ni en desorden, como la equívoca. Acepta varias interpretaciones, pero ordenadas según una jerarquía de mejor a peor. Con esto obtienen la seriedad de la unívoca pero con la apertura de la equívoca, sin caer en ninguno de esos dos extremos"43.

42 Beuchot, Tratado de hermenéutica analógica..., 23-24.

43 Beuchot, "El uso de la hermenéutica y la analogía en el derecho”, 27 y 28 
Como vemos, la ontología es indispensable en la construcción de un derecho humanista y sobre todo en el diseño de una hermenéutica analógica. Se trata de una ontología diferente a la de Alain Badiou, de carácter cuantitativista y centrada en las matemáticas 44 . También es diferente de la ontología posmoderna diseñada para la inmanencia y el debilismo. 45 La ontología analógica le da un particular significado al nexo entre lo individual y lo universal, dado que entiende que cada persona representa a toda la especie, con todas sus limitaciones y su grandeza. Así vemos que cada ser humano se convierte en un sujeto crítico para interpretar la dialéctica, buscando una salida proporcional a los conflictos entre contrarios sin anclarse en una síntesis unívoca. El objetivo ha sido evitar la violencia y la guerra ante el enfrentamiento de los opuestos. Esta idea de la dialéctica nos puede ofrecer desde su analogización una manera diferente de concebir la ontología. Por eso dice Beuchot que "la dialéctica es una de las formas de la analogía”. ${ }^{6}$ Ya que estamos viviendo en la contradicción, lo cual lo podemos sentir en nuestra vida cotidiana.

"Necesitamos, pues, una ontología analógica, que no tenga la pretensión rigorista de las ontologías unívocas de la modernidad, pero que tampoco se derrumbe en la desesperación disolvente de las ontologías equívocas de la posmodernidad. Una que tenga fuerza bastante para salir de la debilidad y la ambigüedad de las ontologías al uso, que más bien no son ontologías (si bien se las mira). Una ontología abierta, pero resistente; una ontología seria, pero abierta, es decir, no reduccionista como la del positivismo, pero tampoco irreductible, como muchas de la posmodernidad" 47 .

Esta ontología toma como punto de partida el pensamiento aristotélico, tomásico, blochiano y beuchotiano exploradores del significado y del sentido y de la propia referencia, de la identidad y de la diferencia, de

44 Alain Badiou, Breve tratado de ontología transitoria (Barcelona, Editorial Gedisa, 2002), 3750.

45 Gianni Vattimo, Adiós a la verdad (Barcelona, Editorial Gedisa, 2010), 41-50

46 Mauricio Beuchot, Dialéctica de la analogía (México, Paidós, 2016), 11.

47 Beuchot, Reflexiones filosóficas sobre los derechos humanos..., 104 y 105. 
lo universal y de lo particular; pero accesible y franca, lejana del irracionalismo de los autores debilistas, narrativistas y metafóricos, con su manifiesto desdén y desprecio a la experiencia, la verdad, la esencia, la iconicidad y lo justo.

Es una ontología jurídica de lo concreto basada en la praxis social humana. Una ontología analógica orientada a abordar los grandes temas del ser. No es unívoca ni equívoca, sino icónica, en la que por medio del conocimiento de un fragmento podemos encontrar el todo. Los derechos humanos están necesitados de una ontología más sencilla establecida en la analogía, la cual está pletórica de sentido48. Se trata de una postura filosófica que prioriza el ser por encima de la norma y en el método de la sutileza, en hegemonía sobre el cuantitativismo y el individualismo metodológico.

"La hermenéutica jurídica, al ser el instrumento de la interpretación del texto jurídico, tiene como objeto un texto que se ha procurado hacer con cuidado, pero que no deja de tener ambigüedades y lagunas, las cuales son sus dificultades. Estas dificultades no se pueden superar con una hermenéutica unívoca, como la que se intentó en el positivismo lógico, cuando se llegó a pensar que se podía formalizar el derecho y llevarlo a una exactitud ideal. Fue el tiempo de la lógica jurídica exacta y de la semiótica jurídica, siempre útiles, pero que nunca llenar las pretensiones que tuvieron. Uno recuerda los centros que se fundaron para llevar a cabo esas empresas de axiomatización o, por lo menos, de búsqueda de rigor que tuvieron que abandonarse" 49 .

Se trata de una sociedad virtuosa por encima de una sociedad de sólo normas y tribunales. La hermenéutica jurídica que defendemos entiende que el ser humano es ante todo un ser social, es decir, un conjunto de relaciones sociales. Comprende que tiene que ir más allá de la descripción para interpretar y transformar con la idea de configurar la esperanza.

48 Mauricio Beuchot, Hermenéutica analógica y ontología (Cuernavaca, CIDHEM, 2013), 151152.

49 Beuchot, "Hacia una hermenéutica jurídica analógica", 52. 
Para ello tiene que ir más lejos, que otras propuestas filosóficas y jurídicas del tipo del Círculo de Viena de Rudolf Carnap50 y de la llamada Escuela de Viena de Hans Kelsen ${ }^{5}$. Ambas agrupaciones se ligaron al positivismo lógico y normativista, siendo presas fáciles del cientificismo, el fisicalismo, el matemáticismo, para ser caldo de cultivo de un supuesto liberalismo igualitario. Una hermenéutica jurídica de nuevo tipo, contempla una sociedad humana en tanto territorio donde lo unívoco se convierta en análogo, la estática en dialéctica, la ilusión se convierta en una realidad concreta y el amanecer ontológico nos conduzca a un mundo mejor.

También es importante la ética, ya que una democracia en busca del bien común debe comprender históricamente la función del bien y del mal, se explora una ética de carácter icónico, distante de las éticas rígidas del pensamiento analítico y sistémico sin caer en las éticas permisivas de la posmodernidad. La tarea es comprender al hombre, tratando de acomodar de manera amable las normas pertinentes; cosa nada frecuente en la época presente. El desafío es esquivar una ética inhumana opuesta a la ontologicidad del hombre. Se asiste en la actualidad a un giro ético en el marco del derecho y los derechos humanos; se habla de códigos de ética en las empresas y en las instituciones públicas. Se trata de una ética para la competencia, el intercambio mercantil, los partidos políticos y el negocio ${ }^{52}$. Muchas profesiones universitarias plantean la necesidad de contar con una formación moral en nombre de los derechos humanos. Existen maestrías y doctorados donde se aborda tal problemática. Incluso se establecen guerras e invasiones basando su táctica y estrategia en los llamados derechos humanos. Es claro que se amparan en las éticas formales de corte absolutista y en las éticas equivocistas.

50 Rudolf Carnap, "Psicología en lenguaje fisicalista en Alfred Ayer", en El positivismo lógico, ed. por Alfred Jules Ayer (México-Buenos Aires: Fondo de Cultura Económica, 1981), 171-250.

51 Robert Walter, "Hans Kelsen vida y obra. Una introducción", Anales 41 (2011): 332-337.

52 Eduardo Soto Pineda y José Antonio Cárdenas Marroquín, Ética en las organizaciones (México: Mc-Graw Hill, 2007), 1-22. 
"Pero también hemos visto que depende mucho del tipo de ética con lo que se vincule al derecho para que resulten diferentes los derechos humanos que dependen y viven de esa vinculación. Es necesario relacionarlos con una ética analógica, que no tenga el univocismo de la ética formal ni el equivocismo relativista de la ética material, y que también escape al univocismo de le ética liberal y del equivocismo de la ética comunitarista, reuniendo las éticas de la justicia y las del bien o de la vida buena en una búsqueda de la defensa y promoción de la vida humana" ${ }^{3}$.

Como vemos, no es pertinente adoptar una concepción de la ética únicamente como actitud a priori, que sólo nos lleve a una concepción maniquea del bien y del mal. Tampoco es viable asumir la "ideología ética”, en tanto respuesta abstracta a toda consideración sobre los derechos humanos, pretendiendo resolver toda contradicción a la luz de un retorno unidimensional "al hombre", al margen del sistema de producción mercantil. La posibilidad de generar una auténtica ética de la liberación tiene que generar un compromiso participante en los movimientos sociales de nuestro tiempo, tal como lo ha planteado el filósofo y teólogo argentino Enrique Dussel54. Este proceso transita en la desconfianza por la edificación imaginaria, es decir, ideológica del discurso, sobre el nexo de la moral con los derechos humanos. En esa vía toma cuerpo la posibilidad de construir una ética de las verdades de hechura fronética, la cual puede ser proporcionada por la analogía y la hermenéutica55. En esta concepción de la ética se agruparán, la ética de la jurisprudencia y la ética de valores, así como la ética de normas y la ética de principios; la ética de la interpretación y la ética de la transformación; la ética judicial y la ética legislativa, así como la ética de los derechos humanos y la ética de los derechos fundamentales.

53 Beuchot, Reflexiones filosóficas sobre los derechos humanos, 80 y 81.

54 Enrique Dussel, Ética de la liberación en la edad de la globalización y de la exclusión (Madrid: Editorial Trotta, 1998), 91-166.

55 Mauricio Beuchot, Ética (México: Editorial Torres, 2004), 123-156. 
También es pertinente el papel de la cimentación en el marco de los derechos humanos. En ella se ha generado un conflicto entre el derecho natural y el positivo. El iusnaturalismo ha partido de un establecimiento ontológico del derecho y de los derechos humanos, a partir de la naturaleza humana. El positivismo lo combate dándole prioridad a la positivación. Sobre esto dice Beuchot lo siguiente:

La principal objeción que los iuspositivistas han esgrimido contra el iusnaturalismo y la ley natural es la acusación de la falacia naturalista que desde Hume, pasando por Moore y llegando a la actualidad, sostiene que fundamentar los derechos humanos en una naturaleza humana, esto es, una ley natural es realizar un paso indebido, a saber, el del ser al deber ser. Pero ya se ha visto que no existe tal falacia, y que incluso tenemos la obligación de partir del estudio del hombre para saber qué derechos humanos le corresponden" 56 .

A nuestro juicio, la naturaleza humana y en lo fundamental el hombre es el punto de partida de una ciencia del derecho y una jusfilosofía pertinente; obviamente sostenida en una estructura ontológica basada en un reconocimiento económico, social y político. Es por eso que el ser humano, es un ser en camino, un homo viator, buscador de la libertad y la justicia, en el marco de los derechos humanos.

Como vemos, los derechos humanos han aparecido debido a la violencia y a la existencia del mercado económico y también de los totalitarismos de todos los colores; por eso lo viviente emerge de lo humano. El hombre es el punto de partida siendo siempre algo incompleto. En este contexto es primordial la dignidad, pues en los últimos cinco milenios, no ha podido construir una sociedad amable, así como se ha visto imposibilitado, para crear una teoría y práctica de los derechos humanos en proporción con su esencialidad, es decir, con su contenido real históricamente determinado.

56 Beuchot, Reflexiones filosóficas sobre los derechos humanos..., 101 y 102. 
"Cuando se dice que los derechos humanos surgen de las necesidades humanas, regresamos a lo mismo, pues las necesidades humanas se basan en la naturaleza humana. Y cuando se dice, más kantianamente, que el fundamento de los derechos humanos es la dignidad humana y esta fundamentación kantiana de tales derechos es hoy por hoy la más aceptada- volvemos a lo mismo: la dignidad humana se basa en la naturaleza humana, está arraigada en ella" 57.

Así se observa que la normatividad naturalista, la llamada ley natural, es el soporte y cimentación de los derechos humanos. Lo interesante es que los derechos morales no se limiten sólo a la positividad; pues su validez no está en función de ser incorporados al derecho positivo, teniendo en un primer plano una trascendencia ontológica y antropológica. Pertenecen a la esencia de la humanidad, con una mayor relevancia que la sintaxis propia de una postura legalista. Un ejemplo de ello es la cuestión de la dignidad. Históricamente tiene mayor sentido y referencia, es decir, mayor significado y conexión como derecho humano, que como estructura legal, al interior de un sistema y ordenamiento jurídico determinado. Es por eso, que el formalismo establece la no conexión de la moral con el derecho, ya que si defienden la primera, tendrían que aceptar la dimensión ontológica del derecho.

"La ley natural, así como el derecho natural, es el fundamento de los derechos humanos para el iusnaturalismo. Algo se acerca a ello la escuela de los Moral Rights, pues, al ser derechos morales, no se quedan en derechos positivos, sino que están más allá de la positivación. Su validez no depende de que sean positivados, y con ello se les retira de ese ámbito jurídico, y pertenecen al ámbito moral, con lo cual se fundamentan -al igual que en la moral- en la antropología filosófica y ésta en la ontología. No nos escapamos de la ontología al buscar la fundamentación filosófica de tan necesarios derechos" ${ }^{8}$.

57 Beuchot, Reflexiones filosóficas sobre los derechos humanos..., 103.

58 Beuchot, Reflexiones filosóficas sobre los derechos humanos..., 103. 
La hermenéutica jurídica que proponemos sigue pensando la ley natural como cimentación concreta, de carácter ontológico y ético en la comprensión de los derechos humanos. La dignidad, la decencia, la honestidad, la integridad y la honorabilidad forman parte de la naturaleza humana; algunos juristas han querido encontrar sustitutos como la norma, la jurisprudencia, el contrato y las garantías. Lo esencial es la naturaleza humana como soporte de la regla naturalista. Obviamente conectada con las relaciones sociales. "Todo esto es muy loable, pero en el fondo se encuentra la naturaleza humana, la ley natural, que parecen ser inescapables"59. Esto es válido y legítimo para una concepción humanista, de los llamados derechos humanos. Es la piedra de toque que distingue una concepción crítica y dialéctica de una posición conformista y domesticada.

\section{CONCLUSIÓN}

Así, nos damos cuenta que la hermenéutica aún es utilizada por la ciencia y la filosofía del derecho, para generar una interpretación lúcida y coherente de sus tópicos fundamentales. También nos percatamos de la visión analógica, como perspectiva humanista para la comprensión de los derechos humanos. La unidad dialéctica está en la hermenéutica analógica, a diferencia de una hermenéutica absolutista que nos llevará a una interpretación cerrada y excluyente, como se genera en el juspositivismo. La hermenéutica relativista sumamente abierta e infinita nos conducirá a la negación de la fundamentación y la universalización de los derechos humanos debido a su postura nihilista. La profunda crisis del derecho moderno y contemporáneo en la comprensión de los derechos humanos, es una muestra histórica de su fragilidad. Por eso es necesario el marco conceptual y metodológico de un humanismo jurídico llamado hermenéutica analógica. De una u otra manera, históricamente se ha

59 Beuchot, Reflexiones filosóficas sobre los derechos humanos..., 108 y 109. 
tenido una actitud contradictoria entre los derechos humanos y la ética, también con la ontología y la antropología. De esta forma, se ha cumplido con la problematización esbozada al inicio de este trabajo, al plantear brevemente un conjunto de hipótesis y tesis sobre la especificidad de los derechos humanos desde un punto de vista objetivo y razonable.

\section{REFERENCIAS BIBLIOGRÁFICAS}

Aguirre Quezada, Juan Pablo. Linchamientos en México. Ciudad de México: Cuaderno de investigación 39, Dirección General de Análisis Legislativo, Instituto Belisario Domínguez, Senado de la República, 2018.

Aristóteles, Política. Madrid: Gredos, 1988.

Badiou, Alain. Breve tratado de ontología transitoria. Barcelona: Editorial Gedisa, 2002.

Baudrillard, Jean. Cultura y simulacro. Barcelona: Editorial Kairós, 1978.

Beuchot, Mauricio. Tratado de hermenéutica analógica. Hacia un nuevo modelo de interpretación, $2^{\mathrm{a}}$. ed. México: UNAM, Itaca, 2000.

-. Ética. México: Editorial Torres, 2004.

-. Filosofía del derecho, hermenéutica y analogía. Bogotá: Universidad de Santo Tomás, 2006.

-. Phrónesis, analogía y hermenéutica. México: UNAM, 2007.

-. Antropología filosófica. Hacia un personalismo analógico-icónico. Salamanca: Colección Persona, 2008.

-. "La hermenéutica analógica en la comprensión de los derechos humanos”. Hiperbórea 1 (2010): 1-16.

-. Reflexiones filosóficas sobre los derechos humanos. México-Madrid: Universidad Nacional Autónoma de México-Tirant lo Blanch, 2018.

Beuchot, Mauricio y Napoleón Conde. Esbozo analógico para el derecho y las ciencias sociales. México: Editorial Torres, 2018. 
Bloch, Ernst. Derecho natural y dignidad humana. Madrid: Biblioteca Jurídica Aguilar, 1980.

-. El principio esperanza, vol. 1. Madrid: Trotta, 2004.

-. El principio esperanza, vol. 2. Madrid: Trotta, 2006.

Calvo, José. Derecho y narración. Materiales para una teoría y crítica narrativista del Derecho. Barcelona: Ariel, 1996.

Carnap, Rudolf. "Psicología en lenguaje fisicalista en Alfred Ayer”. En El positivismo lógico, editado por Alfred Jules Ayer, 171-250. MéxicoBuenos Aires: Fondo de Cultura Económica, 1981.

Crespo, Mariano. "Fenomenología y filosofía del derecho". Pensamiento 72 (2016): 1247-1261

Debord, Guy. La sociedad del espectáculo. Santiago de Chile: Ediciones Naufrago, 1995.

Deleuze, Gilles y Felix Guattari. Mil mesetas: capitalismo y esquizofrenia. Madrid: Editorial Pre-textos, 2004.

Douzinas, Costas. "El fin(al) de los derechos humanos". Anuario de Derechos Humanos. Nueva Época 7 (2006): 309-340.

Dussel, Enrique. Ética de la liberación en la edad de la globalización y de la exclusión. Madrid: Editorial Trotta, 1998.

Ferrajoli, Luigi. Principia iuris, tomo I. Madrid: Editorial Trotta, 2007.

Foucault, Michel. Las palabras y las cosas. Buenos Aires: Siglo XXI Editores, 1968.

Grajewski, Maurice J. “The Formal Distinction of Duns Scotus”. The Philosophical Review 56 (1947): 448-449.

Hobbes, Tomas. De Cive. Madrid: Alianza Editorial, 2016.

Kelsen, Hans. Teoría pura del derecho. México: UNAM, 1982.

-. Teoría general del derecho y del Estado. México: Universidad Nacional Autónoma de México, 2008.

Kilwardby, Robert, De ortu scientiarum. London: British Academy, 1976.

Marx, Carlos y Federico Engels. Manifiesto del Partido Comunista. Moscú: Editorial Progreso, 1969. 
Monsiváis, Carlos. "Los linchamientos: el crimen a nombre de la justicia popular”. Proceso, 14 de septiembre de 1996.

Recaséns Siches, Luis. Introducción al estudio del derecho. México: Editorial Porrúa, 1997.

Rodríguez Guillén, Raúl. "Crisis de autoridad y violencia social: los linchamientos en México”. Polis 8 (2012): 43-74.

Rosillo, Alejandro (coord.). Hermenéutica analógica. Derecho y filosofía. México: Facultad de Derecho de la Universidad Autónoma de San Luis Potosí, 2007.

Soto Pineda, Eduardo y Cárdenas Marroquín, José Antonio. Ética en las organizaciones. México: Mc-Graw Hill, 2007.

Vattimo, Gianni. Adiós a la verdad. Barcelona, Editorial Gedisa, 2010.

Vattimo, Gianni y Santiago Zabala. Comunismo hermenéutico. De Heidegger a Marx. Madrid: Editorial Herder, 2012.

Vyshinsky, Andrey. La teoría de la prueba en el derecho soviético. Montevideo: Editorial Nuevo derecho, 1951.

Walter, Robert. "Hans Kelsen vida y obra. Una introducción”. Anales 41 (2011) 332-337.

Napoleón Conde Gaxiola

EST- Escuela Superior de Turismo

Instituto Politécnico Nacional,

Miguel Bernard 39, La Escalera, 07630

Ciudad de México, CDMX (México)

napoleon_conde@yahoo.com.mx

https://orcid.org/o0oo-0002-8471-2042 